\title{
KAJIAN PENDAYAGUNAAN TENAGA KESEHATAN MASYARAKAT DI KABUPATEN KERINCI PROVINSI JAMBI TAHUN 2016
}

\author{
Study on the Utilization of Public Health Personnel in Kerinci District of Jambi Province in \\ 2016
}

M. Ridwan ${ }^{1}$

${ }^{1}$ Dosen Program Studi Ilmu Kesehatan Masyarakat

Fakultas Kedokteran dan Ilmu Kesehatan Universitas Jambi

\begin{abstract}
Abstrak
Pemanfaatan tenaga kesmas di Industri juga merupakan hal yang perlu dilakukan identifikasi kompetensi apa yang harus di siapkan dalam membuat profil lulusan yang akan di terima pasar kerja. Penelitian ini merupakan penelitian kualitatif dengan design studi kasus, berlokasi di Kabupaten kerinci, dengan populasi seluruh SKM baik itu yang berstatus CPNS, PNS dan tenaga kontrak. Metode pengambilan sampel purposive sampling, variabel penelitian terdiri tenaga SKM, Kompetensi lulusan, peran tenaga SKM, pengambilan data dengan Lokakkarya wawancara mendalam, dan FGD. Analisis Data menggunakan pendekatan content analysis. Tenaga sarjana Kesehatan Masyarakat masih banyak bekerja yang tidak sesuai dengan latar belakang pendidikan peminatan, membuat SKM lebih generalis ada sebuah pilihan agar SKM tidak menjadi Peminatan yang kurang membuat kepercayaan diri bagi SKM. Dengan demikian Profesi adalah pilihan agar membuat SKM lebih berdaya saing. dari hasil wawancara bahwa pendidikan kesmas sangat kurang terhadap praktek sehingga dilapangan mendapat kesulitan di dunia kerja. membuatkan SKPI yang memliki Kompetensi keahlian Khusus sesuai peminatan merupakan solusi dalam persaingan di dunia kerja. Kompetensi SKM yang harus dimiliki menurut responden adalah advokasi, analisis masalah, Aplikasi Komputer, perhitungan biaya, manajemen. pengembangan media, pemberdayaan Masyarakat, pengambilan sample, survey cepat, surveillance, pembiayaan peningkatan kemampuan profesi SKM adalah kemampuan melakukan advokasi kesehatan, dan pemberdayaan masyarakat.
\end{abstract}

Kata Kunci : Kompetensi, SKM, Profesi, Penempatan SKM

\begin{abstract}
The utilization of public health personnel in the industry is also a matter of what competence should be done in preparing the profile of graduates to be received by the labor market. It is a qualitative research with case study design, located in Kerinci district, with population of all undergraduate public health be it candidate of civil servant status, civil servants and contract workers. Sampling method purposive sampling, research variables consist undergraduate public health power, graduate competence, the role of public health bachelor staff, taking data with workshop depth interviews, and FGD. Data analysis using content analysis approach. Public health workforce is still a lot of work that is not in accordance with educational background specialization, making undergraduate public health more generalist there is an option for the public health bachelor not become the less-interested in making confidence for undergraduate public health. thus the Profession is an option to make public health bachelor field gets difficulties in the world of work. make SKPI that possesses Special skill competency according to the specialization is the solution in the competition in the world of work. Public health undergraduate competencies that must be owned by respondents are advocacy, problem analysis, Computer Application, cost calculation, management. media development, community empowerment, sampling, quick survey, surveillance.
\end{abstract}

Keywords : Public health undergraduate competence, profession and placement

Korespodensi : Ridwan

email : ridwannaura@yahoo.co.id 


\section{PENDAHULUAN}

Permasalahan manajemen pelayanan yang dihadapi oleh puskesmas sebagai unit pelayanan dasar tingkat pertama akan berdampak pada pelaksanaan fungsi utamanya yaitu program basic six pelayanan yang terdiri dari pelayanan medis dasar, kesehatan ibu-anak dan keluarga berencana, pencegahan penyakit, penyelenggaraan gizi masyarakat, kesehatan lingkungan dan promosi kesehatan. Permasalahan lain di tingkat puskesmas adalah sumber daya manusia yang terdiri atas tenaga kesehatan dan tenaga penunjang (non tenaga kesehatan). Jenis dan jumlah tenaga kesehatan dan tenaga non kesehatan yang belum sesuai dengan analisis beban kerja, belum pertimbangan jumlah pelayanan yang diselenggarakan, jumlah dan persebaran penduduk, karakteristik wilayah kerja, wilayah kerja, ketersediaan fasilitas pelayanan kesehatan tingkat pertama lainnya di wilayah kerja dan pembagian waktu kerja. (Kementerian Kesehatan RI, 2015). dasar

Era Masyarakat Ekonomi Asean membawa persaingan kompetensi tenaga kesehatan termasuk tenaga kesehatan masyarakat. Pemanfaatn tenaga kesmas di Industri juga merupakan hal yang perlu dilakukan identifikasi kompetensi apa yang harus di siapkan dalam membuat profil lulusan yang akan di terima pasar kerja. Untuk kepentingan tersebut maka Universitas Jambi sebagai penyelenggara institusi pendidikan kesehatan masyarakat melalui Program Studi Kesehatan Masyarakat Fakultas Kedokteran dan Ilmu Kesehatan berkewajiban melakukan kajian dan analisis pendayagunaan tenaga kesehatan Masyarakat sesuai dengan kompetensi yang dibutuhkan oleh masyarakat di institusi di pemerintah dan dunia industri.

\section{METODE}

Merupakan penelitian kualitatif dengan design studi kasus, berlokasi di
Kabupaten kerinci, dengan populasi seluruh SKM baik itu yang berstatus CPNS, PNS dan tenaga kontrak. Metode pengambilan sampel purposive sampling, variabel penelitian terdiri tenaga SKM, Kompetensi lulusan, peran tenaga SKM, pengambilan data dengan Lokakkarya wawancara mendalam, dan FGD. Analisis Data menggunakan pendekatan content analysis.

\section{HASIL DAN PEMBAHSAN}

\section{A. Tugas dan Fungsi tenaga SKM}

Dari hasil penelitian yang dilakukan di dapatkan bahwa sebagian besar tenaga sarjana Kesehatan Masyarakat tidak di letakkan sesuai dengan latar belakang pendidikan mereka bisa bekerja dan di tempatkan sesuai dengan keinginan pimpinan sebuah instansi. dalam pelaksanana pekerjaaan tentunya tenaga SKM membutuhkan penyesuaian untuk tenaga sarjana kesehatan Masyarakat tidak menjadi patokan suatu beban kerja yang mereka kerjakan, Berikut pendapat yang di sampaikan Oleh responden

....kita , kadang dak sesuai dengan pendidikan, kalau pimpinan nyuruh bendahara ya kita laksanakan, kadang kawan ada juga peminatan epid di letakkan di promkes atau sebaliknya..." (s4)

sejalan dengan pendapat yang lain :

......kita mengikuti pimpinan aja mau di letakkan dimana aja..." (s9)

Banyak diantara mereka tenaga Sarjana Kesehatan Masyarakat di posisikan pada bendahara untuk yang di puskesmas pada pengelola BOK atau Jamkesmas setiap hari berurusan dengan pertanggungjawaban keuangan atau 
pada posisi pengadaan dalam suatu instansi, hal ini tentunya kan berpengaruh terhadap kemampuan tenaga Sarjana Kesehatan Masyarakat untuk mengaplikasikan kemampuan nya dalam melakukan, melaksanakan Program kesehatan masyarakat. Pekerjaan Tenaga Sarjana Kesehatan masyarakat tidak begitu ber dampaknya terhadap perkembangan kesehatan masyarakat dikarenakan pada posisi adminstrasi.

berikut Kutipan dari beberapa responden :

......kalau sudah jadi bendahara ya kita jarang tau program karena kita juga pada ngurusin pertanggung jawaban keuangan ...'(s7)

senada dengan pendapat petugas puskesmas lainya :

untuk pengelola keuagan kita tenaga SKM di percaya ya kita laksanakan aja... untuk program kan ada bagiannya ... "(s6)

Beberapa sarjana kesehatan masyarakat ditempatkan sesuai dengan latar belakang pendidikan yang di miliki misalnya bagain epidemiologi dengan latar belakang epidemiologi dan menjadi kepala puskesmas bahkan sampai ke kepala dinas Kesehatan kab/Kota. hal ini sangat menarik kita cermati bagaimana kinerja seorang SKM menjadi kepala puskesmas tentunya menjadi sorotan bagi profesi lainya. hal ini menjadin tantangan bagi SKM menunjukkan hasil yang lebih baik dalam mengelola program maupun dalam mengelola SDM yang ada. hal ini dikemukan responden

... kalau bupati menyetujui kita siap, apapun jabatan yang di berikan "(s13)

beberapa responden mengatakan bahwa

... tidak ada masalah dengan

SKM menjadi Kepala Dinas

Kesehatan maupun kepala puskesmas semua jalan dengan baik...."(s15)

Bila kita lihat permasalahan SKM diatas yang tidak tidak di posisikan sesuai dengan peminatan maka keberhasilan tenaga SKM akan kurang berdampak terhadap pembangunan kesehatan masyarakat. Menurut Thoha (2007), pada dasarnya setiap pegawai mempunyai jabatan karena mereka direkrut berdasarkan kebutuhan utuk melaksanakan tugas dan fungsi yang ada dalam organisasi. Apabila hal ini diikuti, maka tidak akan ada seorangpun pegawai yang tidak mempunyai jabatan apapun jenis jabatannya. untuk itu peran penentu kebijakan sangat menentukan dalam meletakakan seorang dengan keahlian yang mereka miliki. Sejalan dengan pendapat Robbins (2003) analisis pekerjaan adalah mencakup penyususnan suatu urain rinci tugas- tugas yang tercakup dalam pekerjaaan tertentu dengan menentukan hubungan pekerjaaan tertentu 
dengan pkerjaaan lainya dan memastikan pengetahuan, ketrampilan dan kemampuan yang diperlukan bagi karyawan untuk melakukan pekerjaan itu dengan sukseshal yang perlu di kembangkan adalah membuat sarjana kesehatan masyarakat yang generalis dan mengarah ke profesi kesehatan Masyarakat sehinggan sesuai dengan undang - undang tenaga tenaga kesehatan menurut UU No. 12 Tahun 2012 Tentang Pendidikan Tinggi mengatakan bahwa, Pendidikan Profesi adalah pendidikan tinggi setelah pendidikan sarjana, dilaksanakan dengan tujuan peningkatan skill untuk aplikatif . Pendidikan dan profesi harus diterjemahkan ke dalam kompetensi dan kurikulum yang secara khusus mengandalkan pada aplikatif secara dominan. dengan adanaya pendidikan profesi kesmas maka system rekrutmen dan pola pembelajaran akan menjadi lebih linear dan akan berdampak pada kualitas hasil lulusan dan ini akan memberikan kepercayaan diri kepada Tenaga SKM sesuai dengan bidang ahli yang mereka dapatkan.

\section{B. Keahlian/ kompetensi tenaga}

\section{kesehatan Masyarakat}

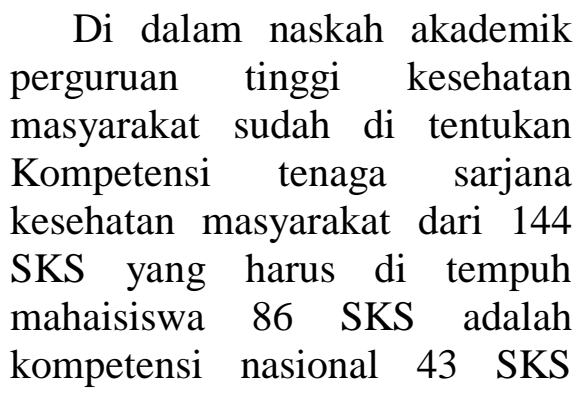

adalah peminatan dan 15 SKS kearifan Lokal untuk menjawab itu maka harus adalah kajian kebutuhan dari stakeholder dari hasil wawancara dengan beberapa responden banyak hal yang dapat diungkapkan mengenai keahlian yang masih belum dilaksnakan dan akan menjadi Fokus proses pembelajaran pada peminatan atau keahlian sarjana kesehatan masyarakat pada umumnya . kemampuan yang di miliki merupakan penciri program studi beberapa jawaban responden tentang Kompetensi tenaga sarjana Kesehstsn masyarakat adalah sebagai berikut :

... untuk tenaga promosi kesehatan yang penting adalah advokasi ya... kemudian media buat film pendek lah, ini wajib sayo kira kemudian pemberdayaan masyarakat,analisis data... (s7)

sejalan dengan responden lainya mengatakan bahwa kompetensi peminatan Promosi kesehatan adalah :

....promkes punya peran di puskesmas... jadi mereka harus bisa media, advokasi , pemberdayaan masyarakat , komunikasi public, presentas dan bisa internet misalnya email, ... (s18)

selain promosi kesehaatan ada peminatan efidemiologi kemampuan yang di milki peminatan epidemiologi ini 
beberapa rsponden yang bekerja di dinas kesehatan maupun puskesmas mengatakan bahwa keahlian yang harus di milki epidemiologi untuk SKM adalah :

$$
\text { .. untuk epidemiologi }
$$
kemampauan surveillance, survey cepat... itu yang dipakai ... dan menganalisi data... (s18)

Pendapat lain mengatakan bahwa seorang SKM pemiantan epidemiologi mampu

ya biasanya yang penting bisa analisis data ... sudah tu survey cepat.... surveylance saya kira itu ... (s25)

Menurut responden sarjana kesehatan masyarakat dengan peminatan administrasi kebijakan kesehatan perlu memiliki keahlian:

...kalau AKK yang penting adalah belajar manajeman yang baik... kemudian pembiayaan kesehatan, kepemimpinan ...(s18)

Responden lainya mengatakan bahwa pemiantan AKK harus mempunyai kemampuan

..ya.. SKM harus bisa ngetik.... membuat renstra dan kalau bisa mampu membaca dokumen RKA APBD maupun ....(s17

Dalam Undang-undang No. 36 Tahun 2014 Tentang Tenaga Kesehatan Pasal 11 ayat 7: Jenis Tenaga Kesehatan yang termasuk dalam kelompok tenaga kesehatan masyarakat adalah : Epidemiologi

Kesehatan, Tenaga Promosi Kesehatan Dan Ilmu Perilaku, Pembimbing Kesehatan Kerja, Tenaga Administrasi Dan Kebijakan Kesehatan, Tenaga Biostatistik Dan Kependudukan, serta Tenaga Kesehatan Reproduksi Dan Keluarga. selanjutnya, Surat keputusan Pengurus Pusat Asosiasi Institusi Pendidikan Tinggi Kesehatan masyarakat Indonesia NO: $\quad 005 / A I P T K M I / I / 2015$ di sebutkan bahwa 86 SKS adalah kurikulm nasional dengan Kompetensi yang telah di tetapkan ada 43 SKS peminatan dan 15 SKS kearifan local. 43 SKS 15 SKS pencirian program studi harus dibuat oleh prodi masing, hal inilah bagaimana kemampuan prodi untuk membaca dan menganalisa kebutuhan pasar kerja serta bagaimana meningkatkan Kompetensi Lulusannya, dengan demikian di harapkan kurikulum yang dibuat berdasarkan kebutuhan stakholser sehingga lulusan SKM dapat melakukan bidang kerja.

Dalam pasal Pasal 35 UU PT No.12/2012 di nyatakan bahwa Kurikulum pendidikan tinggi merupakan seperangkat rencana dan pengaturan mengenaitujuan, isi, dan bahan ajar sertacara yang digunakan sebagai pedoman penyelenggaraan kegiatan pembelajaran untuk mencapai tujuan Pendidikan Tinggi hal ini kemudain di jabarkan lagi dengan panduan penyususnan Kurikulum Perguruan tinggi tahun 2016 (Dirjen dikti, 2016) sehingga nantinya diharapkan sisitem pembelajaran akan terstruktur dengan baik.

Kurangnya Praktek lapangan akan dapat di tutupi bila kurikulum yang di buat 
berdasarakan KKNI dan mengikuti standar DIKTI yang telah di tetapkan. keahlian spesifik lainya tentunya dapat di sikapi dengan memberikan Surat keterangan pendamping ijazah bagi Lulusan sesuai peminatan sehingga mereka mepunyai kemampuan / keahlian khusus agar dapat bersaing di dunia kerja. sesuai dengan Permendikbud nomor 81 tahun 2015 tentang iajazah, sertifikatkompetensi, dan sertifikat profesi pada pasal 1 dinyatakan bahwa Surat Keterangan Pendamping Ijazah yang selanjutnya disingkat SKPI adalah dokumen yang memuat informasi tentang pencapaian akademik atau kualifikasi dari lulusan pendidikan tinggi bergelar.misalnya lulusan peminatan Promkes memilki sertifakiat advokasi, peminatan kesling memilki sertifikat pengambilan sample atau mengambil sertifikat K3 umum hal ini akan memperjelas keahlian yang di miliki setelah lulus di samping nilai akademik yang baik.

\section{KESIMPULAN DAN SARAN}

\section{Kesimpulan}

1. Tenaga Sarjana Kesehatan Masyarakat banyak di tempatkan yang tidak sesuai dengan pendidikan peminatan yang mereka miliki untuk itu system pendidikkan dengan SKM tidak ada peminatan (generalis) yang di mulai pada semester $\mathrm{V}$ lebih tepat. Sistem peminatan yang dilakukan kurang mendapatkan Kompetensi sebagai ahli apa yang mereka miliki. Tenaga SKM merasa Kurang Percaya diri
Tehadap ahli dengan system peminatan yang mereka miliki.

2. Kompetensi tenaga kesehatan masyarakat yang harus di miliki untuk semua peminatan adalah : advokasi, analisis masalah, Analisi Komputer, perhitungan biaya, manajemen. pengembangan media, pemberdayaan Masyarakat, pengambilan sample, survey cepat, surveillance. Menjadi suatu kelemahan dalam system pelajaran Mahasiswa SKM adalah kurangnya Praktek lapangan mereka hanya di beri pembelajaran di dalam kelas. ketika mereka di dunia kerja mereka tidak memilki kemampuan dalam aplikasi pembelajaran yang selama ini mereka tempuh.

\section{Saran}

1. Agar Asosiasi Perguruan Tinggi kesehatan Masyarakat (AIPTKMI) untuk melakukan Perubahan proses pembelajaran dengan SKM tidak peminatan dan mengarah pada Profesi Kesehatan Masyarakat sebagaimana yang di amanatkan Undang-undang

2. Kurikulum yang sedang berjalan pada saat ini agar memperbanyak mahasisiwa praktek lapangan agar mereka memahami pelaksnaan Intervensi berbasis data, terhadap permasalahan kesehatan sebagai contoh bila di sebuah wialayah kerja terjadi wabah DBD apa yang akan meraka kerjakan dari mulai perencanaa, implementasi dan evaluasi 
serta penghitungan biaya yang di butuhkan.

3. Membuat Kurikulum untuk usaha mandiri bagi tenaga SKM sesuai dengan keahlian Profesi

4. Agar mahasisiwa sebelum Lulus dari Kuliah memiliki keahlian Khusus sesuai peminatan yang dituangkan dalam Surat keterangan pendamping Ijazah.

\section{DAFTAR PUSTAKA}

1. Flippo, Edwin. P. 2001. Manajemen Personalia dan Sumber Daya Manusia

2. Gibson, James L, John M. Ivancevich dan James $\mathrm{H}$. Donnelly Jr. 2000. Organizations: Behaviour, Structure and Process, Boston: McGraw-Hill Companies Inc.

3. Bungin, B. (2008) Penelitian kualitatif komunikasi ekonomi kebijakan publik dan ilmu sosial lainya, Jakarta

4. Robbins. Stephen.p (2007) perilaku Organisasi .edisi kesepuluh, penerjemah Benyamin,Indeks,Jakarta

5. Dahlgren.L, Emmelin.M, Winkvist, A. (2004) Qualitative Methodology for International Public Health, print och media, umea University

6. Miles, B.M \& Huberman, M.A. (1992) Analisis Data Kualitatif (Alih bahasa oleh Tjetjep Rohendi, Indonesian Unversity Press, Jakarta

7. Rasiana ,dkk (2014) Analisis Pendayagunaan Tenaga Sarjana Kesehatan Masyarakat Di Rumah Sakit Umum Pusat Dokter Kariadi Kota Semarang Tahun 2013, JURNAL KESEHATAN
MASYARAKAT, Volume 2, Nomor 5, Mei 2014

8. Patton,M.Q.(1991) How to use Qualitative Methods in Evaluation (edisi terjemahan), priyadi,B.P, 2006 (alih bahasa), Metode Evaluasi Kualitatif, pustaka pelajar, Yogyakarta

9. PERMENDIKBUD no 81 tahun 2014 tentang, Ijazah, sertifikat, sertifikat Kompetensi, dan sertifikat profesi

10. Kementerian Kesehatan RI, 2013. Modul Pelatihan Pengangkatan Fungsional Penyuluh Kesehatan Masyarakat (PKM) Terampil. Pusat Promosi Kesehatan- Puslitbang Aparatur, 2013, Jakarta.

11. Kementerian Kesehatan RI, 2014. Kepmenkes RI No. 75 tahun 2014 Tentang Pusat Kesehatan Masyarakat, 2014, Jakarta.

12. Kementerian Kesehatan RI, 2015. Rencana Strategis Pembangunan Kesehatan 2015 2019, Jakarta.

13. Universitas Udayana (2007). Petunjuk Pelaksanaan Tracer Studi. BPMU Bali 2007.Kemenristek Dikti RI (2016). Panduan Penelitian dan Pengabdian Kepada Masyarakat di Perguruan Tinggi. Edisi X tahun 2016.

14. Sugiono, 2013. Penelitian Kualitatif . Jakarta

15. Kementerian Kesehatan RI. Badan Pusat Statistik RI, 2012. Survey Demografi dan Kependudukan Indonesia (SDKI) tahun 2012, Jakarta

16. Ikatan Ahli Kesehatan Masyarakat Indonesia (IAKMI), AIPTKMI (2015). Blue Print Kompetensi Sarjana Kesehatan Masyarakat. Jakarta 2016 
17. Ristekdikti, 2016 Panduan Penyususnan Kurikulum Pendidikan Tinggi, Direktorat Jenderal Pembelajaran dan Kemahasiswaan Kementerian
Riset Teknologi dan Pendidikan Tinggi

18. Permendikbud No. 73 tahun 2013 tentang penyelenggaraan KKNI di Perguruan Tinggi, Jakarta 